\begin{tabular}{ccc}
\hline Sournals & $\begin{array}{c}\text { INTERNATIONAL JOURNAL OF } \\
\text { ORGANIZATIONAL LEADERSHIP }\end{array}$ & $\begin{array}{c}\text { INDUSTRIAL } \\
\text { MANAGEMENT } \\
\text { walm }\end{array}$ \\
\hline \hline
\end{tabular}

\title{
Leader-member exchange and its relationship with career adaptability and job satisfaction among employees in public sector
}

\author{
Fariba Rezapour, Farzad Sattari Ardabili ${ }^{*}$ \\ Department of Management, Ardabil Branch, Islamic Azad University, Ardabil, Iran
}

\section{Keywords:}

Career Adaptability

Public sector, Job

satisfaction, Leader-

Member Exchange

\section{Received}

14 December 2016

Received in revised form 14 June 2017

Accepted

09 September 2017

Correspondence:

Sattari.farzad@gmail.com

\begin{abstract}
Career adaptability has found a special place among the predictive variables of job satisfaction in the recent decade. In fact, the effect of adaptability in different situations may be different depending on factors such as leader-member exchange. In this study, the mediating role of leader-member exchange in the effect of career adaptability was studied using Hayes's fourth model (2013) and collecting 167 samples from the employees of public sector in Ardabil. First, confirmatory factor analysis was performed on the dimensions of career adaptability and leader-member exchange and only two questions of career adaptability questions were removed from the questionnaire due to undesired factor loading. According to the results, job satisfaction and leader-member exchange had the highest correlation with control (one of the dimensions of career adaptability). Moreover, career adaptability and leader-member exchange had the predictive role in job satisfaction $(\mathrm{B}=0.29$ and 0.55 , respectively). The analysis of the mediating role of leader-member exchange was significant $(0.162)$, which indicates that managers of public sector must pay considerable attention to leader-member exchange, so that they can moderate the effect of career adaptability on job satisfaction even if career adaptability is not satisfactory.
\end{abstract}

(C)AIMI Journals

Job satisfaction is of great importance in researches conducted on organizations and more than 5000 studies have been undertaken on this issue in USA since 1992 (Thompson, McNamara, \& Hoyle, 1997). Job satisfaction is a complicated and multi-dimensional concept, which is related to mental, physical, and social factors. According to some researchers, job satisfaction is the complete opposite of emotional exhaustion, which both are considered as career outcomes. Emotional exhaustion is the mental dimension of job satisfaction that can affect personal 
performance. In fact, person's mental improvement will give them job satisfaction. According to researches, supportive relationship with leaders, considered as a high quality relationship in leader-member exchange, will enhance mental ability and motivate people to carry out their duties (Dulebohn, Bommer, Liden, Brouer, \& Ferris, 2012; Seibert, Wang, \& Courtright, 2011). In this theory, leadership is a leader-member exchange. According to this theory, inferiors develop a personal relationship with the superior, which may affect their behavior and attitude towards their job or produce positive career outcomes (Dulebohn et al., 2011).

Job satisfaction is not only affected by organizational factors or those related to the period of employment. Before employment, the person possesses some characteristics related to the desired job and exhibits them within the organization. These factors as well as organizational factors develop relationship with job satisfaction and moderate the effect of organizational factors. Career adaptability as a personal variable may lead to negative effects such as poor job performance, job dissatisfaction (Chang Boon Lee, 2003; McCleese \& Ebi, 2006), and low organizational commitment (McCleese \& Eby, 2006). In fact, in the climax of career adaptability, people cannot act more. However, there is no exact research on the effect of career adaptability on job satisfaction and quitting a job (Chan \& Mai, 2015). According to Savickas (1997), career adaptability means person's readiness to adapt to predefined duties in order to do their job and readiness to adapt to not predefined duties in the work, which is considered as the features of job changes. Previous researches indicate that people exhibiting more adaptability are more satisfied with their career. According to previous studies and features of success in career, career adaptability has a positive relationship with job satisfaction (Chan \& Mai, 2015; Zacher \& Griffin, 2015). This fact confirms the relationship between interpersonal factors and satisfaction, however, this relationship may be affected by organizational factors and leader-member exchange. In fact, leader-member exchange may interfere with the effects of adaptability. According to the theory of career construction, career adaptability is a mental resource and exchange competency helping employees to manage daily work requirements successfully and face changes related to their career effectively (Savickas, 2004). In this theory, all four dimensions of career adaptability, namely concern, control, curiosity, and confidence must help employees to be successful and have positive effect. These four dimensions indicate general resources and strategies used by people to manage duties, transitions, and traumas when constructing their career. Considering the definitions of these dimensions, leader-member exchange may affect them.

In public sector, which are more formal due to the central system and more control, managers must attempt to enhance their employees' satisfaction, since it has a direct effect on peoples' attitude towards the administrative system. Therefore, the conceptual model of this research can be illustrated as presented in Figure 1. 


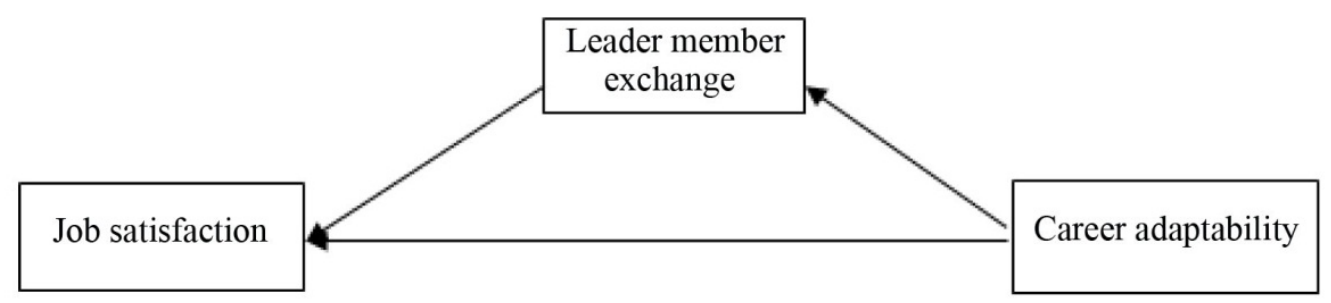

Figure 1. The conceptual model of the research

\section{Method}

\section{Statistical Population and Sampling}

In order to conduct this research, 189 employees of public sector were selected through cluster random sampling and only 154 questionnaires were filled faultlessly and analyzed. All employees were assured that the information within the questionnaires is confidential and anonymous, so that they could answer them safely without any orientation.

\section{Research Tools}

To measure job satisfaction, Michigan Organizational Assessment Questionnaire was used (Cammann, Fichman, Jenkins, \& Klesh, 1983). This questionnaire includes 3 questions which reduces the number of questions within the questionnaire. Moreover, its Cronbach's Alpha is more than 0.89. In this questionnaire, the general feeling about people's job is questioned such as "I am generally satisfied with my job". The third question of this questionnaire includes reverse scoring.

To measure leader-member exchange, Graen's (1995) seven-question questionnaire, which has been developed in previous researches, was used. In this questionnaire, both inferiors and superiors can answer the questions. In order to measure career adaptability, CAAS questionnaire of Savickas and Porfeli (2012) has been applied. This 24-question questionnaire measures four dimensions of career adaptability including concern, control, curiosity, and confidence according to Likert Scale from score one (not strong) to score five (strongest). A sample of these questions is as following: Thinking about how will my future be like (concern), planning to achieve goals (control), studying the surroundings (curiosity), and doing the duties effectively (confidence).

\section{Data Analysis}

First, confirmatory factor analysis (CFA) was performed through varimax rotation to identify the infrastructural dimensions of career adaptability. Since some items of variables in other studies may not be efficient in Iranian organizations, the overlap between items was tested through single-factor exploratory factor analysis, so that the quality of structures would be confirmed.

Principal components analysis and varimax rotation were applied to identify the dimensions of factors. Those factors which their value were higher than 1 were considered (Kaiser, 1958; Kaiser, 1974) and factor with higher than 0.5 factor loading were applied to conclusion. 
Following this, to determine the ratio of factor analysis, Kaiser-Meyer-Olikn measure of sampling adequacy and Bartlett's test were performed.

\section{Results}

\section{The Demographic Description of Sample}

The demographic information of respondents is presented in Table 1. According to Table 1, most respondents were men (78.29\%). Furthermore, most respondents were 31 to 40 and 41 to 50 years old, which indicate that most respondents are middle-aged. Finally, the highest percent of education degree was related to MA.

Table 1

The Demographic Characteristics of Respondents

\begin{tabular}{ll|ll}
\hline Age & Frequency & Education Degree & Frequency \\
\hline $20-30$ & 16.36 & Diploma & 17.63 \\
$31-40$ & 36.36 & Associate degree and BA & 37.01 \\
\hline $41-50$ & 35.15 & MA & 40.91 \\
\hline $51-60$ & 11.52 & $\mathrm{PhD}$ & 4.55 \\
\cline { 2 - 2 } More than 61 & 0.61 & & \\
\cline { 2 - 3 } Gender & Frequency & & \\
Male & 78.29 & & \\
Female & 21.71 &
\end{tabular}

\section{Hypotheses Test}

To test the hypotheses, first second-order confirmatory factor analysis was applied to career adaptability and leader-member exchange. The variable of career adaptability under the title of career path adaptability is very rare in studies and has only been applied to students (such as Salehi, Abedi, Bagheban, \& Nilfrooshan, 2014). In fact, this kind of researches has not been conducted on employees. The variable of leader-member exchange can be affected by uncontrollable variables in the research. The results of confirmatory factor analysis are presented in Table 2.

Table 2

The Results of Confirmatory Factor Analysis for Career Adaptability and Leader-Member Exchange

\begin{tabular}{llc}
\hline & Questions & Factor Loading Value \\
\hline \multirow{5}{*}{ Concern } & Khinking about how will my future be like? & 0.45 \\
& Knowing that my today's decisions will form my future. & 0.50 \\
& Preparing for the future. & 0.75 \\
& Being aware of my educational and occupational alternatives. & 0.50 \\
& Planning to achieve my goals. & 0.74 \\
& Being concerned about my career life. & 0.32 \\
Being always optimistic & 0.38 \\
& Making decisions by myself & 0.69 \\
& Accepting the responsibility for my behavior and acts & 0.70 \\
& Supporting my beliefs & 0.82 \\
& Counting on myself & 0.80
\end{tabular}




\begin{tabular}{|c|c|c|c|}
\hline & \multicolumn{2}{|l|}{ Doing what is right } & 0.76 \\
\hline \multirow{6}{*}{ Curiosity } & \multicolumn{2}{|l|}{ Studying my surroundings } & 0.78 \\
\hline & \multicolumn{2}{|c|}{ Paying attention to opportunities for growth as a person } & 0.73 \\
\hline & \multicolumn{2}{|c|}{ Studying the alternatives before making decision } & 0.81 \\
\hline & \multicolumn{2}{|l|}{ Observing different methods } & 0.80 \\
\hline & \multicolumn{2}{|l|}{ Exploring my questions } & 0.82 \\
\hline & \multicolumn{2}{|l|}{ Being curious about new opportunities } & 0.47 \\
\hline & \multicolumn{2}{|l|}{ Doing the duties effectively } & 0.75 \\
\hline & \multicolumn{2}{|l|}{ Caring about doing the duties well } & 0.79 \\
\hline Confidonco & \multicolumn{2}{|l|}{ Learning new skills } & 0.48 \\
\hline Coninuente & \multicolumn{2}{|l|}{ Working at maximum level } & 0.72 \\
\hline & \multicolumn{2}{|l|}{ Overcoming the obstacles } & 0.82 \\
\hline & \multicolumn{2}{|l|}{ Solving the problems } & 0.83 \\
\hline & \multicolumn{2}{|c|}{$\begin{array}{l}\text { Do you know your position and do you know how the manager will be pleased } \\
\text { with you? }\end{array}$} & 0.53 \\
\hline & \multicolumn{2}{|c|}{ How much is your supervisor aware of your career needs and problems? } & 0.82 \\
\hline & \multicolumn{2}{|c|}{ How much does your supervisor know about your abilities? } & 0.73 \\
\hline $\begin{array}{l}\text { Leader- } \\
\text { member } \\
\text { exchange }\end{array}$ & \multicolumn{2}{|c|}{$\begin{array}{l}\text { Ignoring the position of your supervisor, how much will they use their authority to } \\
\text { solve your problem? }\end{array}$} & 0.80 \\
\hline & \multicolumn{2}{|c|}{ Ignoring the legal power of your supervisor, how much will they support you? } & 0.90 \\
\hline & \multicolumn{2}{|c|}{$\begin{array}{l}\text { I believe in my manager to the extent that even if they are absent, I will } \\
\text { implement their decisions and defend them. }\end{array}$} & 0.70 \\
\hline & \multicolumn{2}{|c|}{ How do you evaluate your working relationship with the supervisor? } & 0.83 \\
\hline \multicolumn{2}{|c|}{ Career Adaptability } & \multicolumn{2}{|l|}{ Leader-Member Exchange } \\
\hline \multicolumn{2}{|c|}{ Chi-Square $=308.79$} & Chi-Square $=54.08$ & RMSEA= 0.11 \\
\hline $\mathrm{NFI}=0.83$ & Cronbach's Alpha $=0.92$ & $\mathrm{NFI}=0.87$ & Cronbach's Alpha $=0.91$ \\
\hline $\mathrm{IFI}=0.90$ & Degree of freedom $=14$ & $\mathrm{IFI}=0.94$ & Degree of freedom $=14$ \\
\hline $\mathrm{TLI}=0.87$ & $\mathrm{CMIN} / \mathrm{DF}=2.38$ & $\mathrm{TLI}=0.89$ & $\mathrm{CMIN} / \mathrm{DF}=3.86$ \\
\hline $\mathrm{CFI}=0.90$ & & $\mathrm{CFI}=0.94$ & \\
\hline
\end{tabular}

According to the table of factor analysis, all components are significant, however, components with higher than 0.4 factor loading value were selected. Thus, questions number 1 and 6 in concern, question number 7 in control (being always optimistic), question number 18 in curiosity, and question number 21 in confidence were deleted from the variable of career adaptability. All the components of leader-member exchange were confirmed. According to Table 2, the values of Chi-Square for the variables of career adaptability and leader-member exchange are respectively equal to 308.79 and 54.08, which indicate the fitness of model. Tucker-Lewis Index for career adaptability and leader-member exchange were equal to 0.81 and 0.94, respectively. Comparative Fit Index for career adaptability and leader-member exchange were equal to 0.84 and 0.94 , respectively, which indicates the fitness of these two variables. According to Table 2, the Root Mean Square Error of Approximation (RMSEA) for career adaptability and leader-member exchange was equal to 0.08 and 0.11 , respectively. Although fit indices for career adaptability were logical, the Root Mean Square Error of Approximation (RMSEA) is one of the best fit indices according to the experts of structural equation modeling (Browne \& Cudeck, 1992). 
The results of Pearson Correlation Test as well as the descriptive indices of variables are presented in Table 3.

Table 3

The Results of Correlation Test for The Variables of the Research and Structures

\begin{tabular}{|c|c|c|c|c|c|c|c|c|}
\hline & 1 & 2 & 3 & 4 & 5 & 6 & Mean & $\begin{array}{c}\text { Standard } \\
\text { Deviation }\end{array}$ \\
\hline Concern & - & & & & & & 3.91 & 0.60 \\
\hline Control & $0.44 * *$ & & & & & & 4.25 & 0.60 \\
\hline Curiosity & $0.58 * *$ & $0.70 * *$ & - & & & & 4.02 & 0.62 \\
\hline Confidence & $0.39 * *$ & $0.65 * *$ & $0.72 * *$ & - & & & 4.20 & 0.58 \\
\hline $\begin{array}{l}\text { Leader-Member } \\
\text { Exchange }\end{array}$ & 0.03 & $0.27 * *$ & 0.14 & 0.13 & - & & 3.35 & 0.80 \\
\hline Job Satisfaction & 0.08 & $0.36^{* *}$ & $0.17 *$ & $0.19 *$ & $0.51 * *$ & - & 1.71 & 0.92 \\
\hline \multicolumn{4}{|c|}{ *Significance Level is 0.05} & \multicolumn{5}{|c|}{ **Significance Level is 0.01} \\
\hline
\end{tabular}

According to Table 3, all the dimensions of career adaptability are correlative and their mean and standard deviation are close to one another. For example, although the mean of concern and control is different (3.91 and 4.25, respectively), their standard deviation is similar (0.6). The mean and standard deviation of leader-member exchange are equal to 3.25 and 0.80 . Furthermore, the mean and standard deviation of employees' job satisfaction indicate that respondents expressed similar opinions ( 3.25 and 0.48 , respectively).

In terms of correlation between variables, all variables showing significant correlation were significant at 0.01 level. According to Table 3, the highest correlation between the dimensions of career adaptability was related to confidence and curiosity (0.72) and curiosity and control (0.70), which indicates the important role of curiosity. The correlation between curiosity and other dimensions of career adaptability was more than 0.5 . However, the correlation between leader-member exchange and three dimensions of career adaptability, namely concern, curiosity, and confidence was not significant and only the dimension of concern showed a significant correlation with leader-member exchange (0.27). Moreover, the correlation between leader-member exchange and job satisfaction was significant (0.51). Job satisfaction was correlated with all dimensions of career adaptability except concern.

Table 4 indicates the results of hypotheses test. Hypotheses 1 and 2 indicate the indirect effect of leader-member exchange on the relationship between career adaptability and job satisfaction. In this hypothesis, it was studied that how different the effect of career adaptability on job satisfaction at different levels of leader-member exchange is. The output of analysis as well as confidence level controlled through Boot Strap method at 95\% level and based on 5000 samples are indicated in Table 4.

Although the effect of career adaptability on job satisfaction is direct, it is not statistically considered significant at $95 \%$ level $(B=0.29, \mathrm{t}=1.75,95 \% \mathrm{CL}[-0.03,0.62])$. According to the confidence level, the direct effect of career adaptability is not significant. However, the direct effect of leader-member exchange is significant $(B=0.55, t=5.36,95 \%$ CL $[0.34,0.75])$.

The predictability of model, which is significant, is presented as following: $(B=0.45, t=2.4$, $95 \%$ CL $[0.086,0.82])$, thus, the indirect effect of career adaptability with the mediating role of leader-member exchange is measurable. 
The regression analysis of mediation through Hayes's method (2013) indicates that the indirect standardized effect of career adaptability on job satisfaction is significant with the mediating role of leader-member exchange, which confirms that leader-member exchange can mediate the effect of this relationship $(\mathrm{B}=0.16, \mathrm{t}=2.09,9 \% \mathrm{CL}[0.029,0.32])$.

For further investigation, Sobel Test and Preacher and Kelley's Test (2011) were conducted. The results of these tests are summarized in Table 5. To ensure that other variables would not affect the relationship between career adaptability and job satisfaction, gender was considered as the control variable in the model. Table 4 shows the the mediating role of leader-member exchange in the relationship between career adaptability and job satisfaction.

Table 4

The Mediating Role of Leader-Member Exchange in The Relationship Between Career Adaptability and Job Satisfaction

\begin{tabular}{|c|c|c|c|}
\hline & \multicolumn{3}{|c|}{ Job satisfaction } \\
\hline & $\mathrm{t}$ & SE & $\mathrm{B}$ \\
\hline Fixed Coefficient & -0.19 & 0.76 & -0.14 \\
\hline Control Variable (Gender) & 0.81 & 0.15 & 0.12 \\
\hline Career Adaptability & $1.75^{*}$ & 0.16 & 0.29 \\
\hline Leader-Member Exchange & $5.36^{* *}$ & 0.10 & 0.55 \\
\hline Career Adaptability * Leader-Member Exchange & 2.09 & 0.07 & 0.16 \\
\hline Sobel Test $Z=1.992$ & & 0.08 & 0.16 \\
\hline Preacher and Kelley's Test (2011) & CL $[0.01,0.18]$ & 0.039 & 0.09 \\
\hline
\end{tabular}

$* \mathrm{P}<10, * * \mathrm{P}<05$

Therefore, it can be claimed that leader-member exchange mediates the effect of career adaptability on job satisfaction. The results of Sobel Test indicate that in standardized conditions, this effect is significant using Boot Strap Method, thus hypotheses 1 and 2 are confirmed. The results of Preacher and Kelley's Test (2011) are positive, which indicates that the model is significant.

\section{Discussion and Conclusion}

The results of the present research indicate that all the dimensions of career adaptability are confirmed in the studied population, however, two questions with undesired factor loading were deleted. Among different dimensions of career adaptability, leader-member exchange and job satisfaction exhibited the highest correlation with control. In terms of job satisfaction, people who have great control over their career can highly control the nature of their job. The nature of job is an internal motivator and is considered as a part of subjective career success (Du Toit\& Coetzee, 2012) and job satisfaction (Westlund, 2008). In most studies such as Tladinyane and Van der Merwe (2016), confidence exhibited the highest correlation with job concern. In the study conducted by Coetzee and Stoltz (2015), the correlation between job satisfaction and concern was significant, however, for other dimensions of career adaptability there was no significant relationship. In their research, job satisfaction exhibited the highest correlation with leader-member exchange. In this research, the correlation between job satisfaction and leader-member exchange was significant as in studies conducted by Gerstner and Day (1997), Rockstuhl, Dulebohn, Ang, and Shore (2012), and Zhang, Wang, and Shi (2012), which indicates that in public sector, leader-member exchange plays an important role 
in improving employees' job satisfaction. Furthermore, career adaptability can affect job satisfaction, thus people with higher career adaptability are more satisfied with their job.

This effect has been confirmed in many studies, however, as in Fiori, Bollmann, and Rossier (2015) its level is different. In this research, leader-member intervened in the relationship between career adaptability and job satisfaction. According to the results, it can be concluded that the more leader-member exchange improves, the more the effect of career adaptability on job satisfaction will improve (the indirect relationship between career adaptability and job satisfaction).

Applying the results of this research, managers can consider career adaptability as a criterion to recruit staff, so that managerial attempts will lead to employees' job satisfaction. Moreover, for employees who have been recruited without considering this factor, managers can help them to enhance job satisfaction and adapt to their career. The dimension of control and its important role in this research indicate that managers must inspire employees to gain more control. This study is of great importance in terms of this dimension, since this research has been conducted in public sector, which indicates that the bureaucratic structure and formality of such organizations may highlight the dimension of control. Therefore, it is recommended that in future studies, all the dimensions of career adaptability in different organizational environments with different cultures be studied, so that it will be found that in these organization how much the dimensions of career adaptability affect job satisfaction and is it possible to consider different conditions for adaptability in different organizations.

\section{References}

Browne, M. W., \& Cudeck, R. (1992). Alternative ways of assessing model fit. Sociological Methods \& Research, 21(2), 230258.

Cammann, C., Fichman, M., Jenkins, G. D., \& Klesh, J. (1983). Michigan organizational assessment questionnaire. In S. E. Seashore, E. E. Lawler, P. H. Mirvis, \& C. Cammann (Eds.), Assessing organizational change: A guide to methods, measures, and practices (pp. 71-138). New York: Wiley-Interscience.

Chan, S. H. J, \& Mai, X. (2015). The relation of career adaptability to satisfaction and turnover intentions. Journal of Vocational Behavior, 89, 130-139.

Chang Boon Lee, P. (2003). Going beyond career plateau: Using professional plateau to account for work outcomes. Journal of Management Development, 22(6), 538-551.

Coetzee, M., \& Stoltz, E. (2015). Employees' satisfaction with retention factors: Exploring the role of career adaptability. Journal of Vocational Behavior, 89, 83-91.

Du Toit, D. M., \& Coetzee, M. (2012). Exploring the perceived career success of staff in a South African science and engineering company. Journal of Psychology in Africa, 27(2), 96-105.

Dulebohn, J. H., Bommer, W. H., Liden, R. C., Brouer, R. L., \& Ferris, G. R. (2012). A meta-analysis of antecedents and consequences of leader-member exchange: Integrating the past with an eye toward the future. Journal of Management, 38(6), 1715-1759.

Fiori, M., Bollmann, G., \& Rossier, J. (2015). Exploring the path through which career adaptability increases job satisfaction and lowers job stress: The role of affect. Journal of Vocational Behavior, 91, 113-121.

Gerstner, C. R., \& Day, D. V. (1997). Meta-analytic review of leader-member exchange theory: Correlates and construct issues. Journal of Applied Psychology, 82(6), 827-844.

Graen, G. B. (1995). Relationship-based approach to leadership: Development of leader-member exchange (LMX) theory of leadership over 25 years: Applying a multi-level multi-domain perspective. The Leadership Quarterly, 6(2), $219-247$.

Hayes, A. F. (2013). Introduction to mediation, moderation, and conditional process analysis: A regression-based approach. New York: Guilford Press.

Kaiser, H. F. (1958). The varimax criterion for analytic rotation in factor analysis. Psychometrika, 23(3), 187-200. 
Kaiser, H. F. (1974). An index of factorial simplicity. Psychometrika, 39(1), 31-96.

Khalili Shourini, S. (1994). The theories of organizational leadership and their application in the management system of Iran. Tehran, Iran: Ghaem Publications.

McCleese, C. S., \& Eby, L. T. (2006). Reactions to job content plateaus: Examining role ambiguity and hierarchical plateaus as moderators. The Career Development Quarterly, 55(1), 64-76.

Preacher, K. J., \& Kelley, K. (2011). Effect size measures for mediation models: Quantitative strategies for communicating indirect effects. Psychological Methods, 16(2), 93-115.

Rockstuhl, T., Dulebohn, J. H., Ang, S., \& Shore, L. M. (2012). Leader-member exchange (LMX) and culture: Ameta-analysis of correlates of LMX across 23 countries. The Journal of Applied Psychology, 97(6), 1097-1130.

Salehi, R., Abedi, M., Bagheban, I., \& Nilfrooshan, P. (2014). Investigation on factor structure, reliability, and validity of career adaptability scale (CAAS). Quarterly of Educational Measurement, 4(16), 49-66.

Savickas, M. L. (1997). Career adaptability: An integrative construct for life-span, life-space theory. The Career Development Quarterly, 45(3), 247-259.

Savickas, M. L. (2004). The theory and practice of career construction. In S. D. Brown \& R. W. Lent (Eds.), Career development and counseling: Putting theory and research to work (pp. 147-183). Hoboken, NJ: John Wiley \& Sons.

Savickas, M. L., \& Porfeli, E. (2012). Career adapt-abilities scale: Construction, reliability, and measurement equivalence across 13 countries. Journal of Vocational Behavior, 80, 744-747.

Seibert, S. E., Wang, G., \& Courtright, S. H. (2011). Antecedents and consequences of psychological and team empowerment in organizations: A meta-analytic review. Journal of Applied Psychology, 96(5), 981-1003.

Thompson, D. P., McNamara, J. F., \& Hoyle, J. R. (1997). Job satisfaction in educational organizations: A synthesis of research findings. Educational Administration Quarterly, 33(1), 7-37.

Tladinyane, R., \& Van der Merwe, M. (2016). Career adaptability and employee engagement of adults employed in an insurance company: An exploratory study. SA Journal of Human Resource Management, 14(1), 1-9.

Westlund, S. G. (2008). Retaining talent: Assessing job satisfaction facets most significantly related to software developer turnover intentions. Journal of Information Technology Management, 19(4), 1-15.

Zacher, H., \& Griffin, B. (2015). Work, aging, and retirement in Australia: Introduction to the special issue. Work, Aging, \& Retirement, 1(2), 129-132.

Zhang, Z., Wang, M., \& Shi, J. (2012). Leader-follower congruence in proactive personality and work outcomes: The mediating role of leader-member exchange. Academy of Management Journal, 55(1), 111-130. 